\title{
Monitor yourself! Deficient error-related brain activity predicts real-life self-control failures
}

\author{
Klaus-Martin Krönke ${ }^{1} \cdot$ Max Wolff $^{1,2} \cdot$ Holger Mohr $^{1} \cdot$ Anja Kräplin ${ }^{1} \cdot$ Michael N. Smolka ${ }^{2,3} \cdot$ Gerhard Bühringer $^{1} \cdot$ \\ Thomas Goschke ${ }^{1,3}$
}

Published online: 13 April 2018

(C) Psychonomic Society, Inc. 2018

\begin{abstract}
Despite their immense relevance, the neurocognitive mechanisms underlying real-life self-control failures (SCFs) are insufficiently understood. Whereas previous studies have shown that SCFs were associated with decreased activity in the right inferior frontal gyrus (rIFG; a region involved in cognitive control), here we consider the possibility that the reduced implementation of cognitive control in individuals with low self-control may be due to impaired performance monitoring. Following a brain-aspredictor approach, we combined experience sampling of daily SCFs with functional magnetic resonance imaging (fMRI) in a Stroop task. In our sample of 118 participants, proneness to SCF was reliably predicted by low error-related activation of a performance-monitoring network (comprising anterior mid-cingulate cortex, presupplementary motor area, and anterior insula), low posterror rIFG activation, and reduced posterror slowing. Remarkably, these neural and behavioral measures predicted variability in SCFs beyond what was predicted by self-reported trait self-control. These results suggest that real-life SCFs may result from deficient performance monitoring, leading to reduced recruitment of cognitive control after responses that conflict with superordinate goals.
\end{abstract}

Keywords Cognitive control $\cdot$ Experience sampling $\cdot$ Individual differences $\cdot$ Performance monitoring $\cdot$ Self-control

In everyday life, people frequently encounter conflicts between their long-term goals, moral values, or social norms, on the one side, and momentary impulses to satisfy immediate desires, on the other. Self-control denotes the ability to resist such temptations and override impulsive responses in order to render behavior consistent with superordinate goals (Baumeister, Vohs, \& Tice, 2007; Hofmann, Baumeister, Förster, \& Vohs, 2012; Inzlicht, Legault, \& Teper, 2014). Whereas high self-control predicts higher educational achievement and social adjustment, better coping with stress, and less substance abuse (Mischel et al., 2010; Tangney,

Klaus-Martin Krönke and Max Wolff contributed equally to this work.

Klaus-Martin Krönke

klaus-martin.kroenke@tu-dresden.de

1 Department of Psychology, Technische Universität Dresden, Zellescher Weg 17, 01062 Dresden, Germany

2 Department of Psychiatry, Technische Universität Dresden, Dresden, Germany

3 Neuroimaging Center, Technische Universität Dresden, Dresden, Germany
Baumeister, \& Boone, 2004), deficient self-control entails harmful behaviors such as overeating and overspending and is a core characteristic of substance use disorders (Bühringer, Wittchen, Gottlebe, Kufeld, \& Goschke, 2008; Goschke, 2014; Heatherton \& Wagner, 2011). Self-control failures (SCFs) thus incur severe personal and societal costs, due to poor health, disability, and early death (Schroeder, 2007; Wittchen et al., 2011). Investigating the neurocognitive basis of individual differences in self-control is therefore of great scientific relevance.

Self-control requires the individual to suppress prepotent responses leading to unwanted behaviors (e.g., to eat cake, smoke a cigarette), and thus is assumed to depend on response inhibition, a cognitive control process associated with the right inferior frontal gyrus (rIFG; Aron, Robbins, \& Poldrack, 2014; Goschke, 2014). Consequently, impaired self-control is commonly thought to reflect the reduced implementation of cognitive control (e.g., Heatherton \& Wagner, 2011; Hofmann, Schmeichel, \& Baddeley, 2012). In line with this view, two previous studies yielded evidence that real-life SCFs related to smoking (Berkman, Falk, \& Lieberman, 2011) and eating (Lopez, Hofmann, Wagner, Kelley, \& Heatherton, 2014) are associated with reduced activity in the 
rIFG in a response inhibition task. In contrast to these studies, which focused on the neural correlates of sustained inhibitory control across a task, here we aimed to investigate the role of error processing as an indicator of performance monitoring. Errors indicate performance failures - that is, actions that run counter to one's intentions - and therefore signal a strong need for subsequent behavioral adaptations in order to continue goal-directed behavior (Danielmeier \& Ullsperger, 2011). Thus, instead of sustained inhibitory control across tasks, here we focused on dynamic adjustments in situations in which increased control was needed. Moreover, we did not restrict data acquisition to a certain (clinical) type of SCF (such as smoking). Rather, aiming at a general understanding of selfcontrol, we addressed SCFs in the context of a wide range of different desires.

On the basis of current neurobiological models of cognitive control, we assume that self-control rests on a performancemonitoring network (PMN) comprising the posterior medial frontal cortex (pMFC), which includes the anterior middle cingulate cortex (aMCC) and the presupplementary motor area (preSMA), as well as the anterior insulae (aINS) (Uddin, 2015; Ullsperger, Danielmeyer \& Jocham, 2014). Although methodological challenges (e.g., spatial smoothing, group differences, image resolution) make a clear functional localization within the pMFC difficult, functional magnetic resonance imaging (fMRI) studies have consistently shown that the pMFC is sensitive to evaluative signals (King, Korb, von Cramon, \& Ullsperger, 2010; Ridderinkhof, Ullsperger, Crone, \& Nieuwenhuis, 2004; Ullsperger \& von Cramon, 2004). Likewise, there is converging evidence that the often coactivated aINS assigns salience to behaviorally relevant stimuli and events (Craig, 2009; Klein et al., 2007; Uddin, 2015).

In line with conflict-monitoring theory (Botvinick, Braver, Barch, Carter, \& Cohen, 2001; Kerns et al., 2004; Miller \& Cohen, 2001), we assume that the PMN registers conflictinduced performance problems and signals the need for enhanced cognitive control and appropriate adjustments to the lateral prefrontal cortex. In the context of response interference tasks such as the Stroop, flanker, or Simon task, these adjustments include recruitment of the rIFG, which mediates the inhibition of prepotent but nonintended responses (Aron et al., 2014). On a behavioral level, these adjustments of cognitive control are reflected in posterror slowing (PES) - that is, the tendency to slow down after an error (Danielmeier \& Ullsperger, 2011; King et al., 2010; Rabbitt, 1966; Ullsperger et al., 2014).

According to the function of performance monitoring outlined above, a hypoactive PMN should lead to reduced recruitment of cognitive control, not only under laboratory conditions but also in real-life situations requiring self-control: For instance, a dieter who views a fast food commercial may fail to inhibit intrusive food-related thoughts, thus allowing a problematic desire to emerge. In such situations, aberrant performance monitoring would entail an inability to efficiently mobilize cognitive control processes, and thus likely leads to full-blown SCFs.

Following a brain-as-predictor approach (Berkman \& Falk, 2013), here we tested whether everyday SCFs assessed via experience sampling are predicted by the neural correlates of performance monitoring, operationalized as error-related brain activity in a Stroop task under fMRI. On the basis of the assumption that SCFs result from deficient monitoring of performance problems and/or insufficient subsequent control adaptations, we hypothesized that low self-control would be associated with (i) low error-related activity in the PMN (aMCC, preSMA, aINS), (ii) low posterror recruitment of the rIFG, and (iii) reduced PES. To determine the discriminant validity of these neural and behavioral measures of performance monitoring with respect to self-ascribed self-control abilities, we furthermore investigated whether error-related brain activity and PES explain variance in SCFs beyond what is predicted by participants' self-reports of trait self-control.

\section{Materials and method}

\section{Participants}

A total of 142 young adults ( 79 female, 63 male; age 20 to 26 years, $M=22.04$ years, $S D=1.73$ ) were recruited from a representative community sample for an ongoing longitudinal study on the role of cognitive control in the onset and early course of addictive disorders. Thus, although addiction was not the focus of the present investigation, participants were screened for symptoms of addictive disorders and addictionlike behaviors (see Appendix 1). Participants were excluded if they had a limited ability to provide informed consent and to understand the questionnaires and tasks, disorders that might influence cognition or motor performance (e.g., craniocerebral injury, multiple sclerosis), magnetic-resonance contraindications, lifetime schizophrenia or psychotic symptoms, bipolar disorder, somatoform, anxiety, obsessive-compulsive or eating disorders, or major depression in the last four weeks. Participants were paid $€ 40$ for completing the scanning session and experience sampling. All participants provided written informed consent. One participant was excluded due to technical problems during the fMRI acquisition; two participants were excluded due to error rates of $100 \%$ in the Stroop task, and 20 participants were excluded due to a complete lack of errors. We excluded one further participant whose parameter estimates deviated from the normal distribution. Thus, 118 participants (64 females, 54 male; age 20-26 years, $M=$ $22.18, S D=1.82$ ) were included in the analyses reported here. This sample size is exceptionally large in comparison to previous studies that have used a brain-as-predictor approach. 


\section{Experience sampling procedure}

Real-life SCFs across a wide range of behavioral domains were assessed via experience sampling (Hofmann, Baumeister, et al., 2012). Participants were given identical smartphones on which a customizable experience-sampling application was running while all other functions were blocked. Participants were shown how to use the device during a brief meeting with a research assistant. The experiencesampling period, during which the participants carried the devices with them at all times, started the next morning and lasted for seven consecutive days. Each day, eight alarms were emitted within a 14-h time window, which was adjusted to the participant's habitual waking hours (starting at either 8,9 , or 10 a.m.). The exact time for each alarm was randomly selected, with the constraint that two alarms be at least $1 \mathrm{~h}$ apart. Whenever participants accepted an alarm, they completed a short questionnaire consisting of up to seven questions on the device. First, they were asked whether or not they had experienced a desire to enact a realizable behavior at some point during the last hour. If they reported a desire, they were asked to indicate the desire strength, on a scale from 1 (very weak) to 6 (very strong), and to select the respective desire type, from a list of 19 categories (eating, drinking, drinking alcohol, smoking, using some other substance, using the internet, playing a computer game, watching TV, buying something, gambling, exercising, sleeping, resting, retreating, misbehaving, socializing, having sex or intimacy, using a bathroom, and other). They were then asked whether they had a reason not to enact the desire (i.e., whether there was a conflict). If they reported a conflict, they were asked to indicate the conflict strength, on a scale from 1 (very weak) to 6 (very strong), and whether or not they had attempted to resist the desire. Eventually they were asked whether or not they had enacted the desired behavior. In summary, up to four dichotomous variables (desire, conflict, resistance, and enactment), one categorical variable (desire type), and two continuous variables (desire and conflict strength) were acquired per questionnaire. Depending on response rates, each participant completed up to 56 questionnaires. SCFs were operationalized as occasions on which the participant failed to resist temptation - that is, enacted a conflict-laden desire.

\section{Self-reports of trait self-control}

Participants' self-evaluations of trait self-control were assessed with a German version of the Brief Self-Control Scale (BSCS; Bertrams \& Dickhäuser, 2009; Tangney et al., 2004). The BSCS comprises 13 items (e.g., "I am good at resisting temptation"; "People would say that I have iron self-discipline"; "Sometimes I can't stop myself from doing something, even if I know it is wrong") and is one of the most widely used questionnaires in self-control research (Duckworth \& Kern, 2011). High BSCS scores indicate high levels of trait self-control.

\section{Stroop task and computation of PES}

Error-related brain activity was measured using blood-oxygen level-dependent (BOLD) fMRI in a counting Stroop task (Bush et al., 1998), with a rapid event-related design. Figure 1 illustrates an exemplary sequence of trials. Each trial started with the presentation of a fixation cross with a jittered

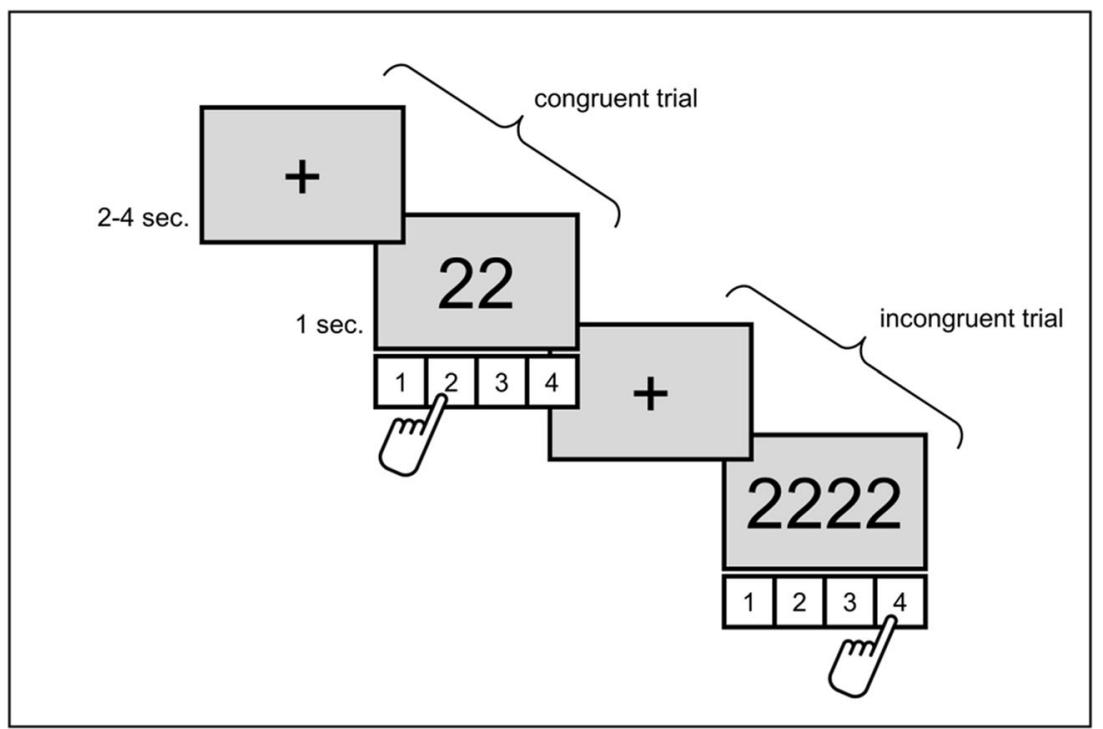

Fig. 1 Exemplary sequence of two trials in the counting Stroop task. After a jittered interstimulus interval $(2-4 \mathrm{~s})$, a row of identical digits was shown. Participants had to indicate the number of digits while ignoring the digits' denotations by pressing one of four response keys.
The number and denotation of the digits were either congruent (" 1 ," "22," "333," "4444”) or incongruent ("111," "2222," "3," “44”). In all, 40 congruent and 40 incongruent trials were presented in randomized order 
duration of $2-4 \mathrm{~s}(2.0,2.5,3.0,3.5$, or $4.0 \mathrm{~s})$. The fixation cross was then replaced by a row of either one, two, three, or four identical digits from 1 to 4 for $1 \mathrm{~s}$, yielding an average trial duration of $4 \mathrm{~s}$. Participants held the index and middle fingers of both hands over four response buttons and were instructed to respond as quickly as possible to the number of digits while ignoring the denoted numbers. The stimulus-response mapping was natural: a one-digit stimulus required a response on the leftmost button, a two-digit stimulus required a response on the second-leftmost button, and so forth. The task-relevant number of digits and the task-irrelevant denotation of the digits were either congruent (" 1, ," 22, ," "333," " 4444 ") or incongruent (“111," "2222," "3," “44”). A total of 80 trials (40 congruent, 40 incongruent) were presented in a randomized sequence, yielding a total task duration of $5 \mathrm{~min}$ 20 s. To clarify the task, participants completed a practice session of 15 trials inside the scanner before the actual experiment started.

As Dutilh et al. (2012) have demonstrated, PES calculated in the traditional way (posterror vs. postcorrect) is prone to global fluctuations in response times (RTs) over the course of the experiment. To reduce noise and minimize the impact of global RT fluctuations, we applied the robust method of PES calculation (Dutilh et al., 2012): The mean RT of correct preerror trials was subtracted from the mean RT of correct posterror trials $\left[R T\left(E_{+1}\right)-R T\left(E_{-1}\right)\right]$ (Table 1). Only the RTs from correct pre- and posterror trials were used for the PES calculation. For each participant, the $z$-standardized PES score was incorporated into subsequent hierarchical linear modeling (HLM) analyses predicting real-life SCFs as a Level-2 predictor (see below).

\section{fMRI data acquisition and analysis}

Functional images were acquired using a $\mathrm{T} 2 *$-weighted gradient-echo echo-planar imaging (EPI) sequence $(\mathrm{TE}=25$ $\mathrm{ms}, \mathrm{TR}=2 \mathrm{~s}$, flip angle $78^{\circ}$, slice thickness $3.2 \mathrm{~mm}$, matrix $64 \times 64$, FOV $19.2 \mathrm{~cm}$, in-plane resolution $3 \times 3 \mathrm{~mm}$ ) on a Siemens MAGNETOM Trio A Tim 3-T scanner with a 32channel head coil. Thirty-four axial slices, oriented parallel to the AC-PC line covering the whole brain, were acquired. In addition, high-resolution anatomical images were acquired (TE

Table 1 Behavioral results of the Stroop task across participants $(N=$ 118)

\begin{tabular}{|c|c|c|c|c|c|}
\hline \multicolumn{2}{|c|}{$\mathrm{RT}(\mathrm{ms}, M \pm S D)$} & \multicolumn{2}{|c|}{$\mathrm{PES}(\mathrm{ms}, M \pm S D)$} & \multicolumn{2}{|c|}{$N$ Errors $(M \pm S D)$} \\
\hline Congruent & Incongruent & $\begin{array}{l}\text { Pre- } \\
\text { Error }\end{array}$ & Posterror & Congruent & Incongru \\
\hline 05 & $656=$ & 91 & 99 & $1.02 \pm 1.6$ & $2.99 \pm 2.48$ \\
\hline
\end{tabular}

$\mathrm{RT}=$ response time, $\mathrm{PES}=$ posterror slowing, $\mathrm{ms}=$ milliseconds
$=2.26 \mathrm{~ms}, \mathrm{TR}=1,900 \mathrm{~ms}$, flip angle $9^{\circ}$, matrix $256 \times 256$, FOV $25.6 \mathrm{~cm}, 176$ sagittal slices, slice thickness $1 \mathrm{~mm}$ ) and coregistered with the functional images. SPM8 (www.fil.ion.ucl. ac.uk/spm/) was used for preprocessing and statistical analyses of the fMRI data. After realignment and slice-time correction (to the middle slice), the data were normalized to standard Montreal Neurological Institute (MNI) space, using a unified segmentation approach based on the separation of gray matter, white matter, and cerebrospinal fluid (voxel size $3 \mathrm{~mm}$ ). The data were spatially smoothed using an 8-mm full-width at halfmaximum (FWHM) Gaussian filter. For baseline correction, the data were high-pass-filtered with a cutoff period of $128 \mathrm{~s}$.

We derived whole-brain measures of error-related brain activity by estimating a general linear model (GLM) of BOLD activity, which included six regressors of interest: (i) congruent correct trials, (ii) incongruent correct trials, (iii) congruent error trials, (iv) incongruent error trials, (v) postincongruent error trials, and (vi) postincongruent correct trials. ${ }^{1}$ Motion parameters were included as regressors of no interest, and the regressors were convolved with a canonical form of the hemodynamic response. Two first-level single-subject contrasts were computed to assess the neural correlates of error processing during and after error commission: an error contrast (incongruent error vs. incongruent correct trials), and a posterror contrast (postincongruent error vs. postincongruent correct trials). ${ }^{2}$ The corresponding contrasts for congruent errors were not calculated because of the low number of errors on congruent trials (see Table 1). At the second level, group contrasts were computed using one-sample $t$ tests on both of the previously described single-subject contrasts.

\section{Extraction of parameter estimates from regions of interest (ROIs)}

At first we confirmed that the PMN was activated during error trials and that the rIFG was activated during posterror trials

\footnotetext{
${ }^{1}$ Regressors $i v$ (incongruent error) and ii (incongruent correct) were modeled in order to assess error-related brain activity during the Stroop task. Congruent errors (iii) were rare and possibly reflect a different process that is not comparable with errors in incongruent trials, which occurred under high cognitive demand. Still, congruent errors were modeled in order to improve our model. Regressors $v$ (postincongruent error) and $v i$ (postincongruent correct) were modeled in order to assess posterror activity, which should reflect the implementation of cognitive control. Regressor $i$ (congruent correct) was also modeled in order to improve our model. Both congruent and incongruent trials were included in regressors $v$ and $v i$. Across participants, we observed no significant difference between the proportions of incongruent trials in postincongruent correct trials $(49.14 \%)$ and postincongruent error trials $(47.19 \%), t(117)=0.575, p=.566$. Thus, conflict levels were equal for both trial types.

${ }^{2}$ Different approaches were applied for the calculation of posterror brain activity (posterror vs. postcorrect) and posterror slowing (PES; posterror vs. preerror) because fMRI data have very low temporal resolution and are thusunlike PES (Dutilh et al., 2012) - barely affected by global RT fluctuations on the observed scale.
} 
(see the Results and Appendix 2 for whole-brain activations). Then we defined ROIs as the overlap between the anatomical masks and task activity, thresholded at $p<.001$ (FWEcorrected, whole-brain). We constructed one mask for the PMN (bilateral MCC, SMA, and INS; Uddin, 2015; Ullsperger et al., 2014) and a second mask for the rIFG (pars triangularis, pars orbitalis, and pars opercularis; Aron et al., 2014) using the Automated Anatomical Labeling (AAL) toolbox (Tzourio-Mazoyer et al., 2002). Since we were exclusively interested in error-related brain activity within the PMN and rIFG ROIs, parameter estimates were extracted from those voxels that were significantly activated in the respective contrast (error or posterror contrast) and that overlapped with the respective mask (PMN or rIFG).

The Marsbar Toolbox (http://marsbar.sourceforge.net/) was used to extract raw parameter estimates. For each participant, $z$-standardized parameter estimates were incorporated into the HLM analyses as Level-2 predictors.

\section{Integration of fMRI and experience sampling data with hierarchical linear modeling}

To test whether error-related brain activity and PES predicted SCFs while taking into account the nested structure of the experience sampling data, fMRI, behavioral, and experience sampling data were subjected to multilevel regression analyses, using the Hierarchical Linear Modeling software package (HLM 7; Raudenbush, Cheong, Congdon, \& DuToit, 2011). Since desire enactment indicates a lack of self-control only when the desires are at conflict with superordinate goals, only those situations in which such a conflict was reported were analyzed. Because the dependent variable, enactment, was binary, logistic multilevel regression analyses were applied using the Bernoulli model in the HLM. For each analysis, a hierarchical two-level model was built with situations (Level 1) nested within participants (Level 2). In each model, the Level-1 predictors were person-mean centered, whereas the Level-2 predictors were grand-mean centered. To avoid overparameterization and keep computational complexity low, only significant random variance components were kept in the models (Hox, 2010).

In a first step, a basic model was built to examine how behavior enactment was affected by desire strength and conflict strength, while controlling for possible effects of desire content by including desire type as a set of effects-coded variables at Level 1. In a second step, this basic model was extended by incorporating individually averaged parameter estimates from the PMN (aMCC, preSMA, aINS) and the rIFG, as well as PES slowing scores as $z$-standardized Level-2 predictors. To avoid problems due to collinearity among the predictor variables, three separate analyses were applied in which only one Level2 predictor at a time was included. In a third step, each of these three models was extended by including $z$-standardized BSCS scores as a second Level- 2 predictor.

\section{Results}

\section{Experience-sampling response rates}

On average, participants responded to $42.83(S D=10.17)$ of the 56 issued alarms. They reported $30.64(S D=10.53)$ desires, $10.48(S D=6.33)$ of which were conflict-laden. SCFs were operationalized as all occasions on which the participant failed to resist temptation and enacted a desire that conflicted with a long-term goal. Of the conflict-laden desires, 5.64 ( $S D$ $=4.67$ ) were reported to result in SCFs, on average (for a categorization of occasions by desire types, see Appendix 3).

\section{Behavioral results of the Stroop task}

Table 1 shows RTs and numbers of errors for the different conditions of the Stroop task. As is commonly found in Stroop experiments, increased RTs, $t(117)=24.753, p<$ .001 , and errors, $t(117)=12.38, p<.001$, were found on incongruent as compared to congruent trials: In the incongruent condition, the mean RT was increased by $51 \mathrm{~ms}(S D=23)$, and the mean number of errors was increased by $1.97(S D=$ 1.73). Moreover, significant PES (using the robust method; Dutilh et al., 2012) was observed following incongruent errors $(M=34 \mathrm{~ms}, S D=106), t(117)=3.49, p<.001 .^{3}$ No corresponding PES effect was observed following congruent errors $(M=-10 \mathrm{~ms}, S D=123), t(57)=-0.43, p=.669$.

Significant PES was also observed when using the traditional method for calculation (posterror minus postcorrect; $M=34 \mathrm{~ms}$, $S D=106 \mathrm{~ms}), t(117)=3.49, p<.001$. PES calculated in this way was not correlated with error-related activity in either the PMN $(r$ $=.115, p=.215)$ or $\mathrm{rIFG}(r=.102, p=.271)$ and did not significantly predict SCFs ( $b_{\log }=-0.102, p=.116$, one-sided).

Note that PES was not accompanied by posterror changes in response accuracy (PIA): Response accuracy was $94.6 \%$ on trials following incongruent hits and $96.1 \%$ on trials following incongruent errors; thus, there was a posterror accuracy increase of $1.5 \%$. This increase was not statistically significant, $t(117)=1.33, p=.187$. Note, however, that the interpretability of PIA in this dataset is limited due to a marked ceiling effect in postincongruent error response accuracies (104 of 118 participants showed a response accuracy of $100 \%$ on trials following incongruent errors; Danielmeier \& Ullsperger, 2011).

\footnotetext{
${ }^{3}$ Across participants, we observed no significant difference between the proportions of incongruent trials in pre- (53.55\%) and posterror trials (47.19\%), $t(117)=1.257, p=.211$. Distortion of PES by unequal conflict levels in preand posterror trials can thus be excluded.
} 


\section{Error-related brain activity}

Figure 2 shows whole-brain activations $(p<.001$, FWEcorrected) in the error and posterror contrasts. As expected, the PMN was activated on error trials, and the rIFG was activated on posterror trials. Global peak activations in the error- and posterror contrasts were located in the right aINS (30/20/- 8) and the rIFG (57/26/- 2), respectively (for all peak activations, see Appendix 2). Correlations with PES were nonsignificant for errorrelated brain activity in both the PMN $(r=.115, p=$ $.216)$ and $\mathrm{rIFG}(r=.091, p=.329)$.

\section{Prediction of SCFs}

Situational variables First, the effects of the situational variables, desire strength and conflict strength, on the occurrence of SCFs were examined without considering any predictors on the second level (Table 2). As one would expect (Hofmann, Baumeister, et al., 2012), the frequency of SCFs increased with desire strength $\left(b_{\log }=0.40, p<.001\right)$ and decreased with conflict strength $\left(\mathrm{b}_{\mathrm{log}}=-0.78, p<.001\right)$ : SCFs were most likely in situations in which desire strength was high and/or conflict strength was low.

Error-related brain activity and PES Consistent with our first prediction, we observed that participants showing weaker activation in the PMN ( $b_{\log }=-0.20, p=.018$, one-tailed) on error relative to correct trials were more likely to commit SCFs than were participants showing stronger error-related activation of the PMN (Table 2 and Fig. 3). Consistent with our second prediction, SCFs were also significantly predicted by activity in the rIFG on posterror trials: More SCFs were reported by participants showing weaker posterror activation in the rIFG ( $\mathrm{b}_{\log }=-0.25, p=.004$, one-tailed) (Fig. 3, Table 2). Consistent with our third prediction, we found that reduced PES predicted more SCFs ( $\mathrm{b}_{\log }=-0.19, p=.013$, one-tailed $)$.

Note that (despite reduced sample sizes) the results remained consistent when participants were excluded who committed only one error on incongruent trials $(n=81$; PMN: $b_{\log }=-0.35, p=.001 ;$ rIFG: $\left.b_{\log }=-0.31, p=.011\right)$, two errors on incongruent trials $\left(n=52\right.$; PMN: $\mathrm{b}_{\mathrm{log}}=-0.42, p$ $=.014 ;$ rIFG: $\left.\mathrm{b}_{\log }=-0.39, p=.047\right)$, or three errors on incongruent trials $\left(n=37\right.$; PMN: $\mathrm{b}_{\log }=-0.44, p=.038$; rIFG: $b_{\log }=-0.44, p=.074$.

In none of the analyzed brain regions did error-related activity significantly interact with desire or conflict strength. Because analyses of correctly performed conflict trials might also be of interest, these results can be found in Appendix 4 . The results for between-group analyses are reported in Appendix 1.

Of note, SCFs were also significantly predicted by higher numbers of incongruent errors $\left(b_{\log }=0.317, p=.013\right)$. Nonetheless, error rates did not explain the effects of errorrelated brain activity and PES on SCFs: Even after including the number of errors as an additional predictor, the effects of

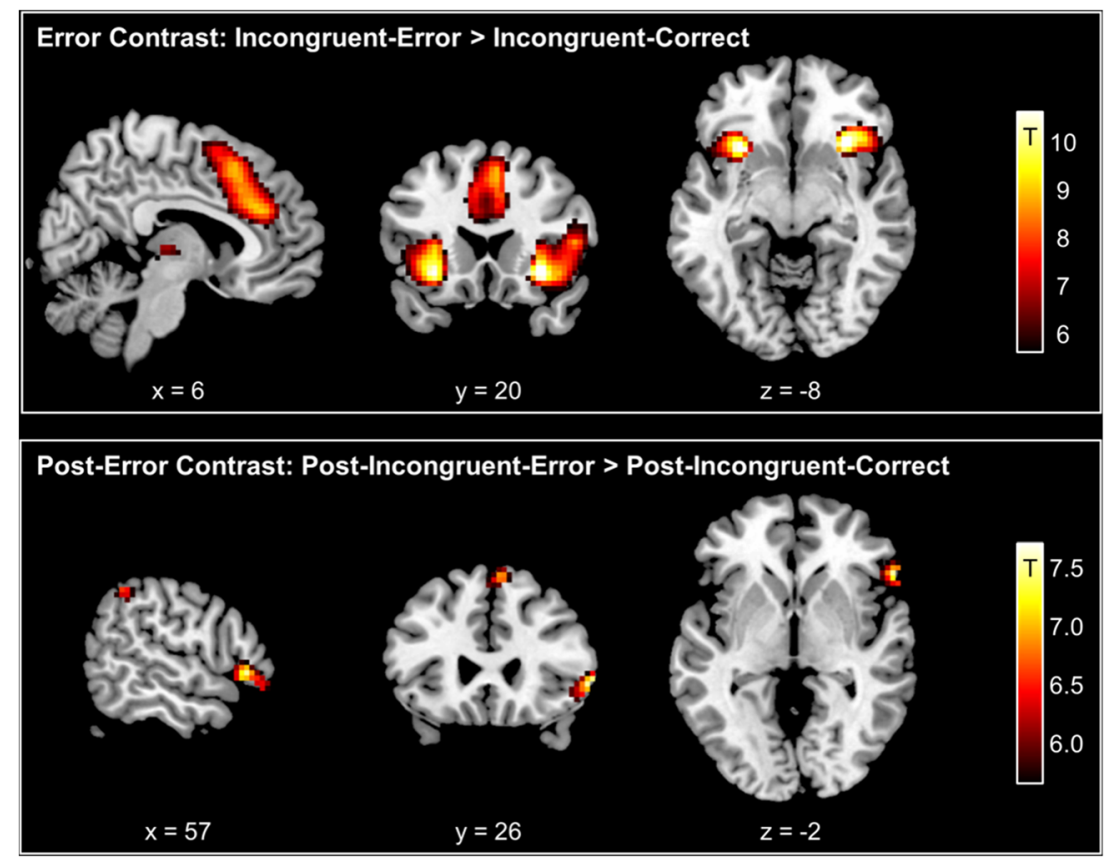

Fig. 2 Whole-brain activations for the error and posterror contrasts, thresholded at $p<.001$ (FWE-corrected; for all peak activations, see Appendix 2). The performance-monitoring network (PMN; including aMCC, preSMA, and aINS) was activated in the error contrast, and the right inferior frontal gyrus (rIFG) was activated in the posterror contrast. Overlaps between these activations and predefined anatomical masks were used as the regions of interest from which parameter estimates were extracted in order to predict self-control failures (see Fig. 3) 
PMN $\left(b_{\log }=-0.189, p=.028\right)$ and $\operatorname{rIFG}\left(b_{\log }=-0.216, p=\right.$ $.015)$ activity, as well as of PES ( $\left.b_{\log }=-0.191, p=.014\right)$, on SCF remained significant. Error rates were not correlated with $\operatorname{PES}(r=-.061, p=.514)$.

Trait self-control The negative main effects of error-related brain activity and PES remained significant when BSCS scores were included as an additional Level-2 predictor (Table 2), showing that these neural and behavioral measures of performance monitoring predicted variability in SCFs that was not explained by trait self-control. SCFs were nonetheless also significantly predicted by BSCS scores in all models: As expected, participants with low as compared to high trait selfcontrol were significantly more likely to commit SCFs. Significant cross-level interactions of BSCS scores with desire and conflict strength indicated that the effect of trait selfcontrol on SCFs was stronger for weak desires and strong conflicts.

\section{Discussion}

The goal of the present study was to further elucidate the neurocognitive mechanisms underlying individual differences in real-life SCFs. Therefore, we combined neuroimaging (fMRI) with ecological assessment of self-control via experience sampling in a large sample of participants. Whereas it is commonly assumed that impaired selfcontrol reflects the reduced implementation of cognitive control, here we investigated the more specific assumption that the reduced implementation of cognitive control during real-life SCFs may result from insufficient mobilization of control processes due to deficient performance monitoring. Consistent with this idea, our results showed that individual differences in real-life self-control were reliably predicted by error-related brain activation in the performance-monitoring network, comprising the pMFC and aINS, posterror activation of the rIFG, and, on a behavioral level, PES. These results suggest that individual differences in real-life self-control reflect variability in both initial (error detection) and subsequent (implementation of cognitive control) components of performance monitoring.

This pattern goes beyond previous reports of associations between SCFs and activation of the rIFG (Berkman et al., 2011; Lopez et al., 2014), and emphasizes the role of performance monitoring in real-life self-control: Consistent with conflict-monitoring theory (Botvinick et al., 2001; Kerns et al., 2004; Miller \& Cohen, 2001), according to which the implementation of cognitive control depends on a signal generated by the PMN, we showed that real-life SCFs were more likely in those individuals who exhibited low error-related activation of the

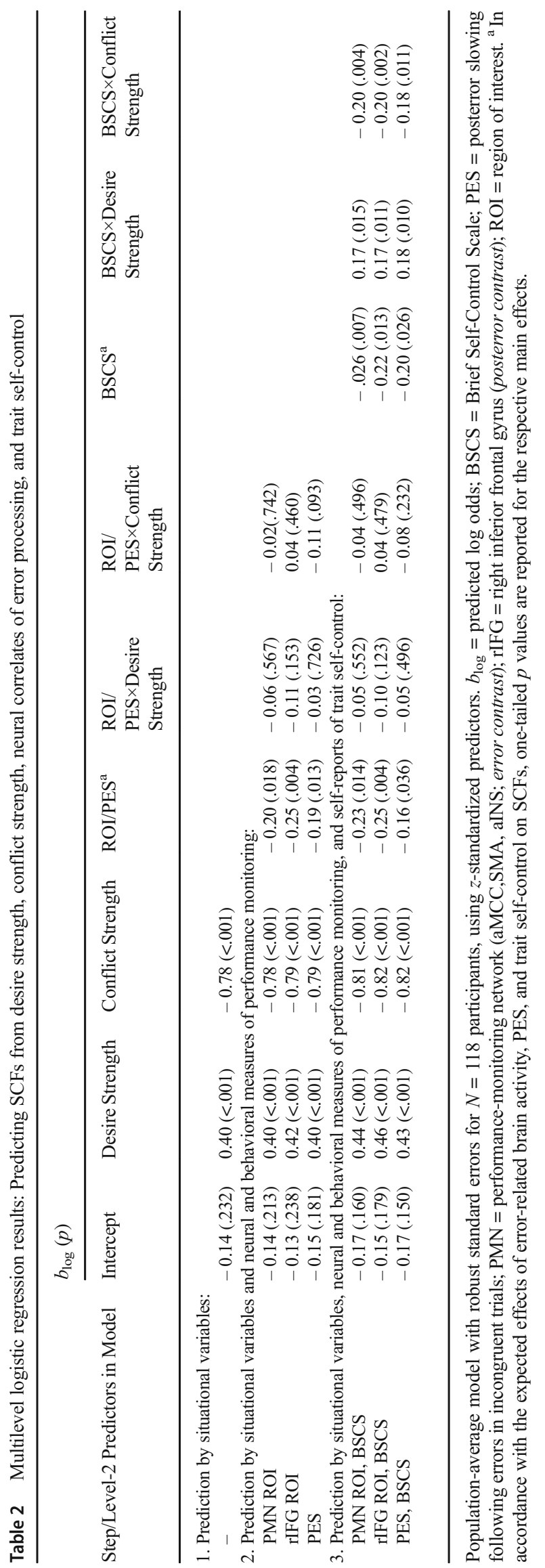




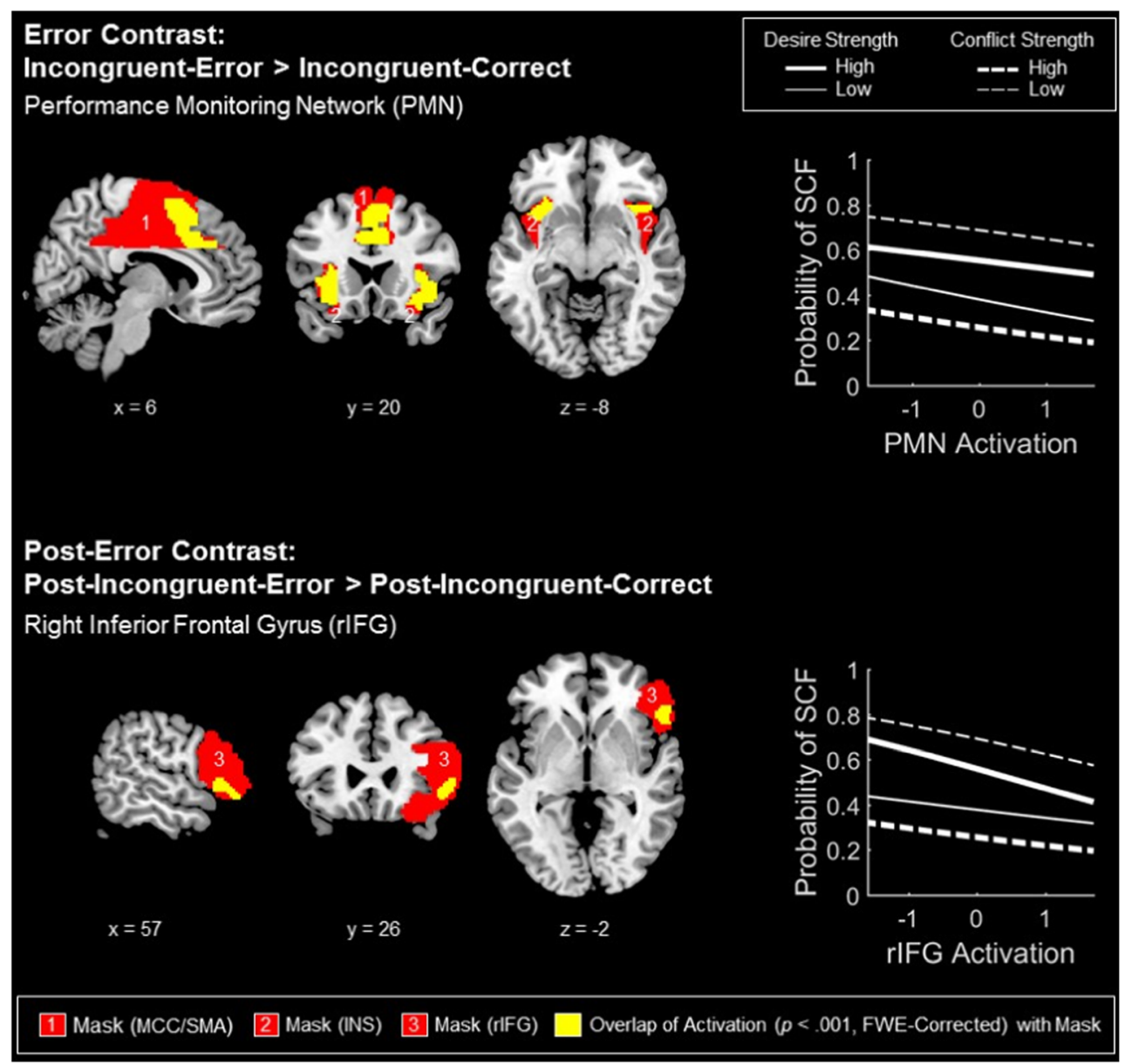

Fig. 3 Effects of error-related performance-monitoring network (PMN) and right inferior frontal gyrus (rIFG) activity, desire strength, and conflict strength on the probability of real-life self-control failures (SCFs). Anatomically defined ROI masks are shown in red in the online figure. Brain activity was extracted from voxels that were significantly activated in response to errors ( $p<.001$, FWE-corrected, whole-brain) and that overlapped with the ROI masks (shown in yellow in online version).

PMN in a Stroop task. This indicates that among individuals with low self-control, unwanted action outcomes or desires conflicting with superordinate goals may be less likely to be detected and/or do not elicit sufficiently strong salience signals, leading to reduced recruitment of cognitive control. Converging, albeit more indirect, evidence supporting this view comes from the fact that PMN dysfunctions are often found in substance-related and addictive disorders, of which impaired self-control is a core characteristic (Carey, Nestor, Jones, Garavan, \& Hester, 2015; Goschke, 2014; Luijten et al., 2014).

Note that although correlates of impaired cognitive control implementation (reduced posterror rIFG activation, reduced PES) also predicted real-life SCFs, this does
Predicted log-odds for SCFs have been transformed into probabilities. The $x$-axes range from the 5 th to the 95 th percentiles of values for PMN activation and rIFG activation, respectively. Separate plots are shown for high (1 SD above the mean) and low (1 SD below the mean) desire and conflict strength. SCFs were less likely to occur with low desire strength or high conflict strength, and in participants who showed stronger PMN and rIFG activations

not necessarily imply a lack of cognitive control competencies in those individuals who act in a less selfcontrolled way. In line with current models of self-control that have incorporated conflict-monitoring theory (Inzlicht, Bartholow, \& Hirsh, 2015; Kotabe \& Hofmann, 2015), less self-controlled behavior could alternatively be explained by reduced mobilization of cognitive control as a consequence of insufficient performance monitoring. This is consistent with the more general view that strong control competencies alone are not sufficient for successful self-control. Instead, even individuals with high capacities for exerting cognitive control may exhibit low self-control if they fail to efficiently mobilize control in response to desire-goal conflicts. 
In contrast to Lopez et al. (2014), we did not find an interaction between desire strength and rIFG activation. Furthermore, we found no interactions between neural and behavioral measures of error processing and conflict strength. This suggests that, in contrast to the ability to exert sustained inhibitory control, which may be especially important when facing strong desires, an efficient mobilization of control is crucial for self-control regardless of desire and conflict strength. An alternative explanation for the lack of interaction with desire and conflict strength is that third variables that are unrelated to desire and conflict strength may explain the observed association between error-related brain activity and SCFs.

We found no correlation between PES and PMN activity. This might be explained by the fact that the PMN as defined in the present study (preSMA, MCC, insula) only partially overlaps with neural substrates described for PES, which, in addition to the preSMA, also include right-hemispheric lateral frontal areas and the subthalamic nucleus (Danielmeier \& Ullsperger, 2011).

Response conflicts and resulting performance problems have been shown to be inherently aversive (Aarts, De Houwer, \& Pourtois, 2012), and this negative affect appears to play a functional role in initiating required adjustments in cognitive control (Dreisbach \& Fischer, 2012; Inzlicht et al., 2015; Saunders, Lin, Milyavskaya, \& Inzlicht, 2017; Wiswede, Münte, Goschke, \& Rüsseler, 2009). This suggests that impaired mobilization of control in self-control situations may reflect a relative inability to process conflict-related aversive states adaptively. Instead of effectively reducing negative affect by mobilizing control, thus addressing the conflict itself and solving it in accordance with superordinate goals, individuals with low self-control may use less conflictcentered emotion regulation strategies or even ruminate about the emotion itself. In line with this conjecture, in a recent study (Wolff et al., 2016) we found that high executive control competencies predicted lower proneness to daily SCFs in individuals with a disposition toward "action orientation" (who have been shown to efficiently recruit control in response to conflict; Goschke \& Bolte, 2018; Kuhl \& Beckmann, 1994), but not in "state-oriented" individuals, who tend to respond to conflicts with rumination rather than enhanced control recruitment (Fischer, Plessow, Dreisbach, \& Goschke, 2015; Jostmann \& Koole, 2007).

Apart from ineffective responses to negative affect, reduced mobilization of control and low error-related PMN activations may also result from low control motivation-that is, a low expected payoff in relation to costs from engaging control (Shenhav, Botvinick, \& Cohen, 2013). Thus, in line with previous evidence suggesting an inverse relationship between cognitive demand avoidance and the efficacy of self-control (Kool, McGuire, Wang, \& Botvinick, 2013), our finding of low error-related brain activity in individuals with low selfcontrol may in part reflect individual differences in effort discounting.

Since SCFs are a core characteristic of various mental disorders such as addiction, depression, and certain anxiety disorders (Goschke, 2014), our study is also of theoretical and practical relevance for clinical conditions: Besides attempts to improve control competencies with, for instance, working memory training (Karbach \& Verhaeghen, 2014; Klingberg, 2010) or training of inhibitory control (Berkman, Kahn, \& Merchant, 2014), patients might also benefit from therapeutic interventions that include modules to strengthen performance monitoring-for example, via mindfulness-based interventions (e.g., Jha, Krompinger, \& Baime, 2007; Mrazek, Franklin, Phillips, Baird, \& Schooler, 2013; Witkiewitz, Bowen, Douglas, \& Hsu, 2013; Saunders, Rodrigo, \& Inzlicht, 2016).

Note that although we showed that predictions based on conflict-monitoring theory yield convincing results with regard to real-life self-control, this does not mean that alternative accounts of cognitive control are less valid. We are aware of the fact that a simple conflict monitoring view has been challenged (e.g., Grinband et al., 2011), and we do not suggest that the role of the medial prefrontal cortex is restricted to a single cognitive function (Ebitz \& Hayden, 2016). Rather, apart from multiple forms of performance monitoring (Neta, Schlaggar, \& Petersen, 2014), the medial prefrontal areas have been implicated in reward processing (Holroyd \& Coles, 2002; Holroyd \& Yeung, 2012), learning (Alexander \& Brown, 2011), execution of control, action selection and computing the value and cost of control (Shenhav et al., 2013). At the same time, however, we stress that our conclusion that real-life SCFs can partly be explained by insufficient performance monitoring leading to reduced behavioral adaptations is neither invalidated by alternative accounts of cognitive control nor inconsistent with accounts according to which brain structures involved in performance monitoring may serve more general functions such as cost-benefit analyses underlying the adaptive regulation of control (Shenhav et al., 2013).

Having shown that everyday SCFs are predicted by neural processes related to performance monitoring and 
cognitive control, the present study demonstrates that brain data serve as an informative window into the psychological processes underlying important real-life behaviors. When following such a brain-as-predictor approach, it is critical to consider whether the predictive information of neural data goes beyond what could be obtained otherwise (Berkman \& Falk, 2013). Here we found error-related brain activity (and PES) to predict variability in SCFs that was not explained by trait self-control, indicating that these measures have unique predictive power and show discriminant validity with respect to self-reports.

A potential methodological limitation of the present study results from the necessity of using a task that produces maximally salient — and thus relatively rare - error events, which might have led to a decreased signal-to-noise ratio in errorand posterror trials. Nevertheless, consistent with current models of cognitive control (Aron et al., 2014; Ridderinkhof et al., 2004; Ullsperger et al., 2014), we found extremely robust task activations related to performance monitoring (aINS, aMCC, SMA) and inhibition (rIFG), even when using a very conservative threshold $(p<.001$ FWE-corrected; see Fig. 2 and Appendix 2) - and these were indeed predictive of reallife self-control. However, to obtain more error trials while preserving error saliency, future studies might employ longer tasks or administer the tasks repeatedly.

To conclude, our findings suggest that real-life SCFs may result from deficient performance monitoring, leading to insufficient recruitment of cognitive control in response to action outcomes that conflict with superordinate goals. The present study adds to the still sparse attempts to bridge the gap between experimental laboratory research and the assessment of real-life self-control using a brain-as-predictor approach and provides further support for the validity of that approach. Although currently correlational, this promising approach allows for identifying possible neurocognitive mechanisms underlying realworld behavioral problems. This may serve as the basis for future prospective and interventional studies testing causal relations and may help improve the prediction, diagnosis, and modification of self-control impairments in mental disorders as well as of maladaptive social and economic behaviors.

Author note T.G. conceptualized the research hypothesis and study design. Data analysis was carried out by K.M.K. and M.W. The manuscript was written primarily by K.M.K. and M.W., with contributions from T.G., H.M., A.K., M.S., and G.B. We thank Joseph A. King for helpful comments on the manuscript. Funding for this research was provided by a grant from the German Research Foundation (DFG) for the Collaborative Research Centre "Volition and Cognitive Control" (SFB
940/1-2015 and SFB 940/2-2016). The authors declare no conflicts of interest.

\section{Appendix 1 Addiction symptoms in the study sample and analysis of group differences}

Participants were recruited to be assigned to one of three groups that differed in terms of symptoms of addictive disorders and addiction-like behaviors: a substancerelated symptoms group (Group A; 26 participants included in final analyses; two or more DSM-5 criteria for alcohol and/or tobacco use disorder), ${ }^{4}$ a non-substancerelated symptoms group (Group B; 38 participants; two or more DSM-5 criteria for gambling disorder and/or adapted criteria for addiction-like behaviors), and a control group (Group C; 54 participants; no more than one criterion of any category). Table 3 summarizes the fulfillment of diagnostic criteria by study participants across the sample.

To explore whether the relationship between SCFs and the neural and behavioral correlates of error processing was affected by group membership, the original multilevel regression models were extended by including two effectcoded dummy variables (indicating membership in Groups A and B) and their interactions with error-related brain activity and PES. Table 4 summarizes the three respective models. Significant interactions were found between membership in the substance-related symptoms group and both PMN and rIFG activity: The substancerelated symptoms group (Group A) showed a stronger effect of PMN activity and a reversed effect of rIFG activity on SCFs. Whereas the stronger PMN effect in the substance group is consistent with the PMN effect across groups, the reversed effect of rIFG activity in the substance group is surprising. Please note that although this exploratory result is potentially interesting and points toward the possibility that substance-related and nonsubstance-related addictions are characterized by related but distinct neurocognitive impairments (Bühringer, Kräplin, \& Behrendt, 2012; Goschke, 2014), we had no hypotheses about between-group effects, since they were not the focus of the present study. Table 5 summarizes results for the participants in the control group only. Note that the parameter estimates for PMN and rIFG in this analysis are consistent with the main results.

\footnotetext{
${ }^{4}$ The estimated time interval (in minutes) since last consumption was not correlated with neural and behavioral measures of error processing for either nicotine (PMN: $r=.00, p=.976$; rIFG: $r=.02, p=.887$; incongruent errors: $r=$ $.09, p=.531$; PES: $r=-.09, p=.527$ ) or alcohol (PMN: $r=-.19, p=.052$; rIFG: $r=-.09, p=.354$; incongruent errors: $r=.16, p=.096$; PES: $r=-.02, p$ $=.837$ ).
} 
Table 3 Numbers of participants fulfilling diagnostic criteria for addictive disorders and addiction-like behaviors

Number of Criteria Fulfilled

\begin{tabular}{|c|c|c|c|c|c|c|c|c|c|}
\hline \multirow{2}{*}{ Addictive Disorder/Addiction-Like Behavior } & & & & & & & & & \\
\hline & 0 & 1 & 2 & 3 & 4 & 5 & 6 & 7 & 8 \\
\hline Nicotine ${ }^{a}$ & 124 & 2 & 1 & 4 & 4 & 1 & 3 & 3 & - \\
\hline Alcohol $^{\mathrm{b}}$ & 88 & 32 & 10 & 6 & 3 & 2 & 1 & - & - \\
\hline Gambling $^{\mathrm{c}}$ & 141 & 1 & - & - & - & - & - & - & - \\
\hline Gaming $^{\mathrm{d}}$ & 126 & 3 & 3 & 2 & 2 & 2 & 2 & 2 & - \\
\hline Internet use $^{\mathrm{d}}$ & 76 & 22 & 15 & 11 & 9 & 5 & 3 & - & 1 \\
\hline Compulsive buying $^{\mathrm{d}}$ & 141 & 1 & - & - & - & - & - & - & - \\
\hline
\end{tabular}

According to the DSM-5, a substance use disorder can be diagnosed when 2 or more criteria for the respective disorder are met. Substance use disorder severity is specified as either mild (2-3 criteria met), moderate (4-5), or severe (6 or more). Gambling disorder can be diagnosed when 4 or more criteria are met. Gambling disorder severity is specified as either mild (4-5 criteria met), moderate (6-7), or severe (8-9). ${ }^{\mathrm{a}}$ DSM-5 nicotine use disorder. ${ }^{\mathrm{b}}$ DSM5 alcohol use disorder. ${ }^{\mathrm{c}}$ DSM-5 gambling disorder. ${ }^{\mathrm{d}}$ These addiction-like behaviors are not recognized as addictive disorders according to DSM-5. Criteria were adapted from DSM-5 criteria for substance use disorders.

Table 4 Multilevel logistic regression results: Predicting SCFs from desire strength, conflict strength, neural correlates of error processing, and group membership

\begin{tabular}{|c|c|c|c|c|c|c|c|c|c|}
\hline \multirow[b]{2}{*}{$\begin{array}{l}\text { Level-2 } \\
\text { Predictor }\end{array}$} & \multicolumn{9}{|l|}{$b_{\log }(p)$} \\
\hline & Intercept & $\mathrm{ROI}^{\mathrm{a}} / \mathrm{PES}^{\mathrm{a}}$ & Group A & Group B & $\begin{array}{l}\text { ROI/PES } \\
\times \text { Group A }\end{array}$ & $\begin{array}{l}\mathrm{ROI} / \mathrm{PES} \\
\times \text { Group B }\end{array}$ & Desire Strength & $\begin{array}{l}\text { Desire Strength } \\
\times \text { ROI/PES }\end{array}$ & $\begin{array}{l}\text { Desire Strength } \\
\times \text { Group A }\end{array}$ \\
\hline $\begin{array}{l}\text { PMN ROI } \\
\text { rIFG ROI } \\
\text { PES }\end{array}$ & $\begin{array}{l}-0.13(.255) \\
-0.08(.502) \\
-0.15(.180)\end{array}$ & $\begin{array}{l}-0.25(.005) \\
-0.13(.188) \\
-0.25(.004)\end{array}$ & $\begin{array}{l}0.12(.443) \\
0.11(.477) \\
-0.01(.935)\end{array}$ & $\begin{array}{l}0.15(.322) \\
0.09(.540) \\
0.21(.138)\end{array}$ & $\begin{array}{l}-0.31(.004) \\
0.47(.001) \\
-0.21(.098)\end{array}$ & $\begin{array}{l}0.26(.054) \\
-0.26(.099) \\
0.04(.717)\end{array}$ & $\begin{array}{l}0.35(<.001) \\
0.39(<.001) \\
0.36(<.001)\end{array}$ & $\begin{array}{l}-0.06(.513) \\
-0.15(.060) \\
-0.06(.368)\end{array}$ & $\begin{array}{l}-0.15(.196) \\
-0.17(.135) \\
-0.18(.057)\end{array}$ \\
\hline \multirow[b]{2}{*}{$\begin{array}{l}\text { Level-2 } \\
\text { Predictor }\end{array}$} & \multicolumn{9}{|l|}{$b_{\log }(p)$} \\
\hline & $\begin{array}{l}\text { Desire } \\
\text { Strength } \\
\times \text { Group B }\end{array}$ & $\begin{array}{l}\text { Desire } \\
\text { Strength } \\
\times \text { ROI/PES } \\
\times \text { Group A }\end{array}$ & $\begin{array}{l}\text { Desire } \\
\text { Strength } \\
\times \text { ROI/PES } \\
\times \text { Group B }\end{array}$ & $\begin{array}{l}\text { Conflict } \\
\text { strength }\end{array}$ & $\begin{array}{l}\text { Conflict } \\
\text { Strength } \\
\times \text { ROI/PES }\end{array}$ & $\begin{array}{l}\text { Conflict } \\
\text { Strength } \\
\times \text { Group A }\end{array}$ & $\begin{array}{l}\text { Conflict } \\
\text { Strength } \\
\times \text { Group B }\end{array}$ & $\begin{array}{l}\text { Conflict } \\
\text { Strength } \\
\times \text { ROI/PES } \times \\
\text { Group A }\end{array}$ & $\begin{array}{l}\text { Conflict } \\
\text { Strength } \\
\times \text { ROI } / \mathrm{PES} \times \\
\text { Group B }\end{array}$ \\
\hline PMN ROI & $-0.01(.909)$ & $0.03(.773)$ & $0.08(.596)$ & -0.78 & $-0.01(.855)$ & $0.01(.929)$ & $-0.03(.761)$ & $0.01(.925)$ & $-0.05(.655)$ \\
\hline rIFG ROI & $-0.03(.760)$ & $0.06(.580)$ & $-0.13(.266)$ & $\begin{array}{c}-0.79 \\
(<.001)\end{array}$ & $0.03(.622)$ & $0.06(.460)$ & $-0.06(.527)$ & $0.16(.102)$ & $-0.18(.107)$ \\
\hline PES & $-0.01(.909)$ & $0.01(.910)$ & $-0.06(.573)$ & $-0.80(.001)$ & $-0.10(.080)$ & $0.02(.825)$ & $-0.05(.600)$ & $0.02(.853)$ & $0.04(.671)$ \\
\hline
\end{tabular}

Population-average model with robust standard errors for $N=118$ participants, using $z$-standardized predictors. $b_{\text {log }}=$ predicted log odds; PES $=$ posterror slowing following errors in incongruent trials, $\mathrm{PMN}=$ performance-monitoring network $(\mathrm{aMCC} / \mathrm{SMA}$, aINS); rIFG = right inferior frontal gyrus; $\mathrm{ROI}=$ region of interest; Group A = substance-related symptoms group; Group B = non-substance-related symptoms group. ${ }^{\mathrm{a}}$ In accordance with the expected effects of error-related brain activity and PES on SCFs, one-tailed $p$ values are reported for the respective main effects. 
Table 5 Multilevel logistic regression results (healthy controls only): predicting SCFs from desire strength, conflict strength, neural correlates of errorprocessing, and trait self-control

\begin{tabular}{|c|c|c|c|c|c|c|c|c|c|}
\hline \multirow[b]{2}{*}{$\begin{array}{l}\text { Step/Level-2 } \\
\text { Predictors } \\
\text { in Model }\end{array}$} & \multicolumn{9}{|l|}{$b_{\log }(p)$} \\
\hline & Intercept & $\begin{array}{l}\text { Desire } \\
\text { Strength }\end{array}$ & $\begin{array}{l}\text { Conflict } \\
\text { Strength }\end{array}$ & $\mathrm{ROI} / \mathrm{PES}^{\mathrm{a}}$ & $\begin{array}{l}\text { ROI/PES } \\
\times \text { Desire } \\
\text { Strength }\end{array}$ & $\begin{array}{l}\text { ROI/PES } \\
\times \text { Conflict } \\
\text { Strength }\end{array}$ & $\mathrm{BSCS}^{\mathrm{a}}$ & $\begin{array}{l}\text { BSCS } \\
\times \text { Desire } \\
\text { Strength }\end{array}$ & $\begin{array}{l}\text { BSCS } \times \\
\text { Conflict } \\
\text { Strength }\end{array}$ \\
\hline \multicolumn{10}{|c|}{ 1. Prediction by situational variables: } \\
\hline & $-0.26(.136)$ & $0.58(<.001)$ & $-0.78(<.001)$ & & & & & & \\
\hline \multicolumn{10}{|c|}{ 2. Prediction by situational variables and neural and behavioral measures of performance monitoring: } \\
\hline PMN ROI & $-0.30(.098)$ & $0.54(<.001)$ & $-0.77(<.001)$ & $-0.23(.107)$ & $-0.21(.093)$ & $0.02(.734)$ & & & \\
\hline rIFG ROI & $-0.20(.251)$ & $0.61(<.001)$ & $-0.80(<.001)$ & $-0.34(.001)$ & $-0.08(.485)$ & $0.05(.455)$ & & & \\
\hline PES & $-0.27(.542)$ & $0.58(<.001)$ & $-0.78(<.001)$ & $-0.09(.271)$ & $-0.03(.673)$ & $-0.14(.136)$ & & & \\
\hline \multicolumn{10}{|c|}{ 3. Prediction by situational variables, neural and behavioral measures of performance monitoring, and self- reports of trait self- control: } \\
\hline PMN ROI, BSCS & $-0.28(.116)$ & $0.52(<.001)$ & $-0.72(<.001)$ & $-0.22(.122)$ & $-0.23(.036)$ & $0.03(.631)$ & $-0.08(.274)$ & $0.22(.015)$ & $-0.20(.02$ \\
\hline rIFG ROI, BSCS & $-0.19(.271)$ & $0.59(<.001)$ & $-0.75(<.001)$ & $-0.35(.001)$ & $-0.08(.365)$ & $0.05(.450)$ & $-0.06(.335)$ & $0.22(.016)$ & $-0.22(.01$ \\
\hline PES, BSCS & $-0.27(.131)$ & $0.55(<.001)$ & $-0.74(<.001)$ & $-0.07(.318)$ & $-0.06(.430)$ & $-0.11(.269)$ & $-0.06(.351)$ & $0.22(.016)$ & $-0.18(.06$ \\
\hline
\end{tabular}

Population-average model with robust standard errors for $N=54$ participants, using $z$-standardized predictors. $b_{\log }=$ predicted log odds; BSCS $=$ Brief Self-Control Scale; PES = posterror slowing following errors in incongruent trials; PMN = performance-monitoring network (aMCC,SMA, aINS; error contrast); rIFG = right inferior frontal gyrus (posterror contrast); ROI = region of interest. ${ }^{a}$ In accordance with the expected effects of error-related brain activity, PES, and trait self-control on SCFs, one-tailed $p$ values are reported for the respective main effects.

\section{Appendix 2 Whole-brain peak activations}

Table 6 Whole-brain peak activations $(N=118, p<.001$, FWE-corrected $)$

\begin{tabular}{|c|c|c|c|c|c|c|}
\hline Contrast & Region & $x$ & $y$ & $z$ & Cluster Size & $T$ \\
\hline \multicolumn{7}{|c|}{ Incongruent error $>$ Incongruent correct } \\
\hline rINS & & 30 & 20 & -8 & 487 & 11.78 \\
\hline rIFGoper & & 51 & 20 & 10 & & 8.68 \\
\hline rIFGtri & & 42 & 17 & 28 & & 6.24 \\
\hline IINS & & -30 & 17 & -8 & 332 & 11.57 \\
\hline IINS & & -30 & 23 & 4 & & 9.79 \\
\hline $\mathrm{ACC}$ & & 6 & 32 & 28 & 822 & 9.06 \\
\hline rSMA & & 6 & 20 & 49 & & 8.90 \\
\hline MCC & & 6 & 23 & 37 & & 8.68 \\
\hline THA & & 6 & -19 & 4 & 38 & 6.81 \\
\hline THA & & -3 & -19 & 4 & & 6.71 \\
\hline BS & & 9 & -25 & -5 & & 5.99 \\
\hline SMG & & 60 & -43 & 25 & 10 & 5.92 \\
\hline BS & & -6 & -25 & -5 & 2 & 5.86 \\
\hline \multicolumn{7}{|c|}{ Postincongruent error $>$ Postincongruent correct } \\
\hline rIFGtri & & 57 & 26 & -2 & 77 & 7.48 \\
\hline rMFG & & 27 & 56 & 25 & 92 & 7.35 \\
\hline $\mathrm{CB}$ & & -45 & -58 & -29 & 121 & 7.22 \\
\hline $\mathrm{CB}$ & & -24 & -70 & -32 & & 6.98 \\
\hline $\mathrm{CB}$ & & -33 & -79 & -29 & & 5.91 \\
\hline rSMA & & 6 & 20 & 61 & 88 & 7.13 \\
\hline rSupFrontMed & & 0 & 29 & 52 & & 6.29 \\
\hline rIPL & & 51 & -46 & 52 & 61 & 6.93 \\
\hline PCL & & 3 & -43 & 70 & 2 & 5.78 \\
\hline
\end{tabular}

Degrees of freedom [1,117]; $\mathrm{r}=$ right; $1=$ left; INS = insula; IFGoper $=$ inferior frontal gyrus, pars opercularis; IFGtri $=$ inferior frontal gyrus, pars triangularis; $\mathrm{ACC}=$ anterior cingulate cortex; $\mathrm{SMA}=$ supplemental motor area; $\mathrm{MCC}=$ middle cingulate cortex; $\mathrm{THA}=$ thalamus; $\mathrm{BS}=$ brainstem; $\mathrm{SMG}=$ supramarginal gyrus; $\mathrm{MFG}=$ middle frontal gyrus; $\mathrm{CB}=$ cerebellum; SupFrontMed = superior frontal medial gyrus; IPL = inferior parietal lobe; $\mathrm{PCL}=$ paracentral lobule 


\section{Appendix 3: Types of desires, conflicts, and self-control failures}

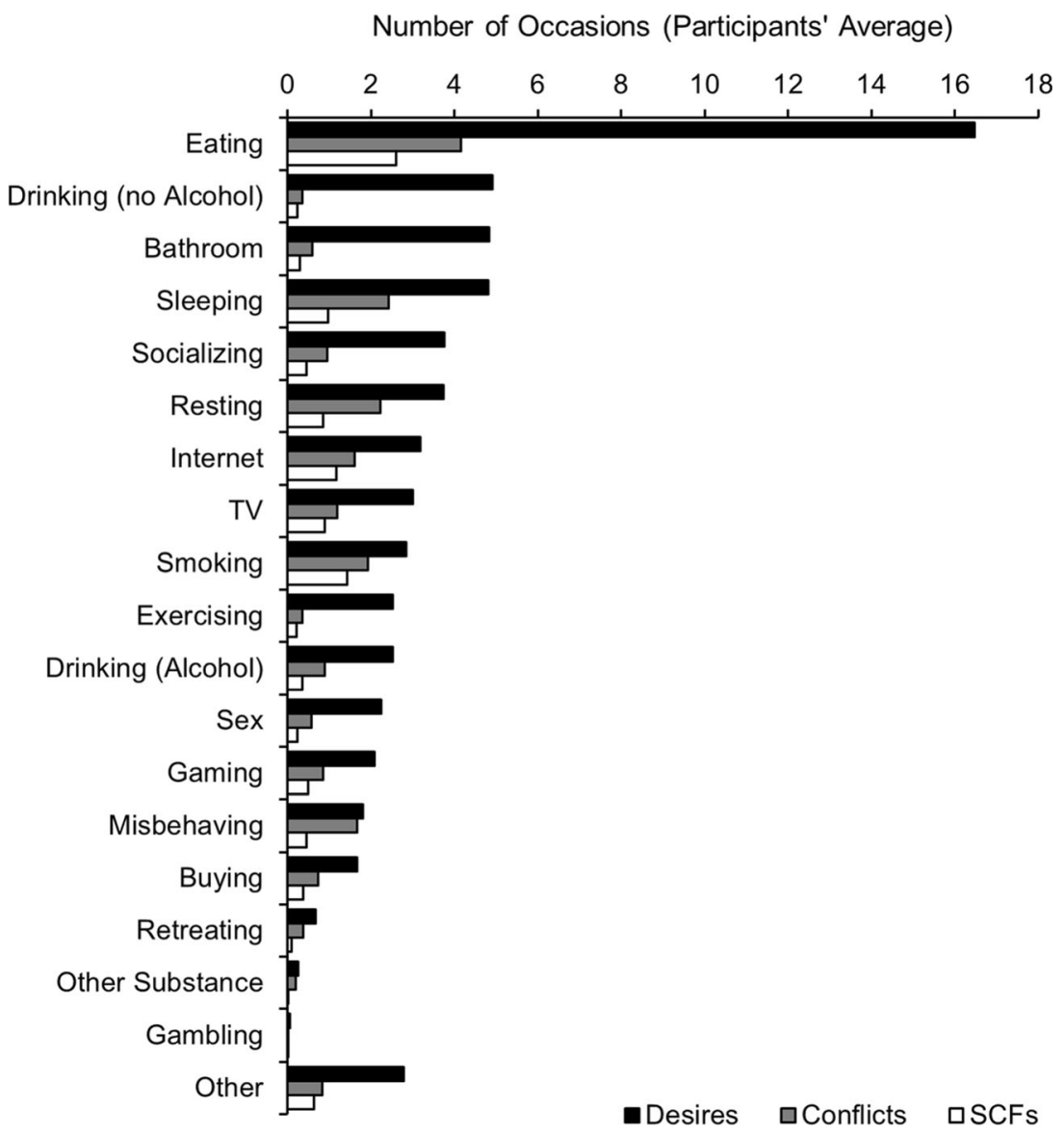

Fig. 4 Total numbers of desires, conflicts, and SCFs reported by the 118 included participants during the experience-sampling period, by desire type.

\section{Appendix 4: Conflict-related brain activity as a predictor of real-life self-control failures}

To investigate whether self-control failures were predicted by brain activity in successfully resolved conflict trials, the same data analysis approach was used as for error-related brain activity. Thus, one additional GLM, two additional fMRI contrasts, and one additional HLM were computed. Since participants without error trials could be included, the sample size for this supplementary analysis was $N=139$ (76 female, 63 male; ages 20 to 26 years, $M=22.03$ years, $S D=1.75$ ).

In addition to the error (incongruent error $>$ incongruent correct trials) and posterror (postincongruent error $>$ postincongruent correct trials) contrasts, a third contrast was computed in order to assess the brain activity associated with resolved conflicts: the resolved-conflict contrast (incongruent correct $>$ congruent correct trials). To investigate BOLD activity after resolved conflicts, a second GLM was estimated, including four regressors of interest: (i) postincongruent correct trials, (ii) postcongruent correct trials, (iii) congruent error trials, and (iv) incongruent error trials. A fourth contrast was computed in order to assess BOLD activity after resolved conflicts: the post-resolved-conflict contrast (postincongruent correct $>$ postcongruent correct trials).

To investigate the brain activity associated with resolved conflicts, the same PMN and rIFG masks were used as for the investigation of error-related brain activity in the original analysis. ROIs were again defined as the overlap between the anatomical masks and task activity, thresholded at $p<.001$, FWEcorrected (whole-brain). Peak activations are listed in Table 7. Note that activations of midcingulate and presupplementary motor areas but not the aINS were found in the resolved-conflict contrast. Parameter estimates were extracted from those voxels within the PMN mask that showed significant activation in the resolved-conflict contrast. Since there was no overlap between task activity in the post-resolved-conflict contrast and the rIFG mask, no parameter estimates could be extracted for this contrast.

Table 8 shows HLM results predicting SCFs from the situational variables and conflict-related PMN activity. In contrast to error-related PMN activity, conflict-related PMN 
activity did not predict real-life SCFs $\left(b_{\log }=0.13, p=.161\right)$. This suggests that the observed association between SCFs and error-related brain activity may have been due to the fact that both real-life desire-goal conflicts and errors (but not resolved conflicts) in a Stroop task are relatively rare, salient events that are perceived consciously. In accordance with this assumption, error but not resolved-conflict trials activated the aINS, which is assumed to play a major role in salience processing (Sridharan, Levitin, \& Menon, 2008; Uddin, 2015) and has been identified as a neural substrate of conscious error awareness (Ullsperger, Harsay, Wessel, \& Ridderinkhof, 2010). Note, however, that conflict-monitoring theory makes no assumptions regarding the conscious awareness of conflictinduced performance problems.

Table 7 Whole-brain activations $(N=139, p<.001$, FWE corrected $)$

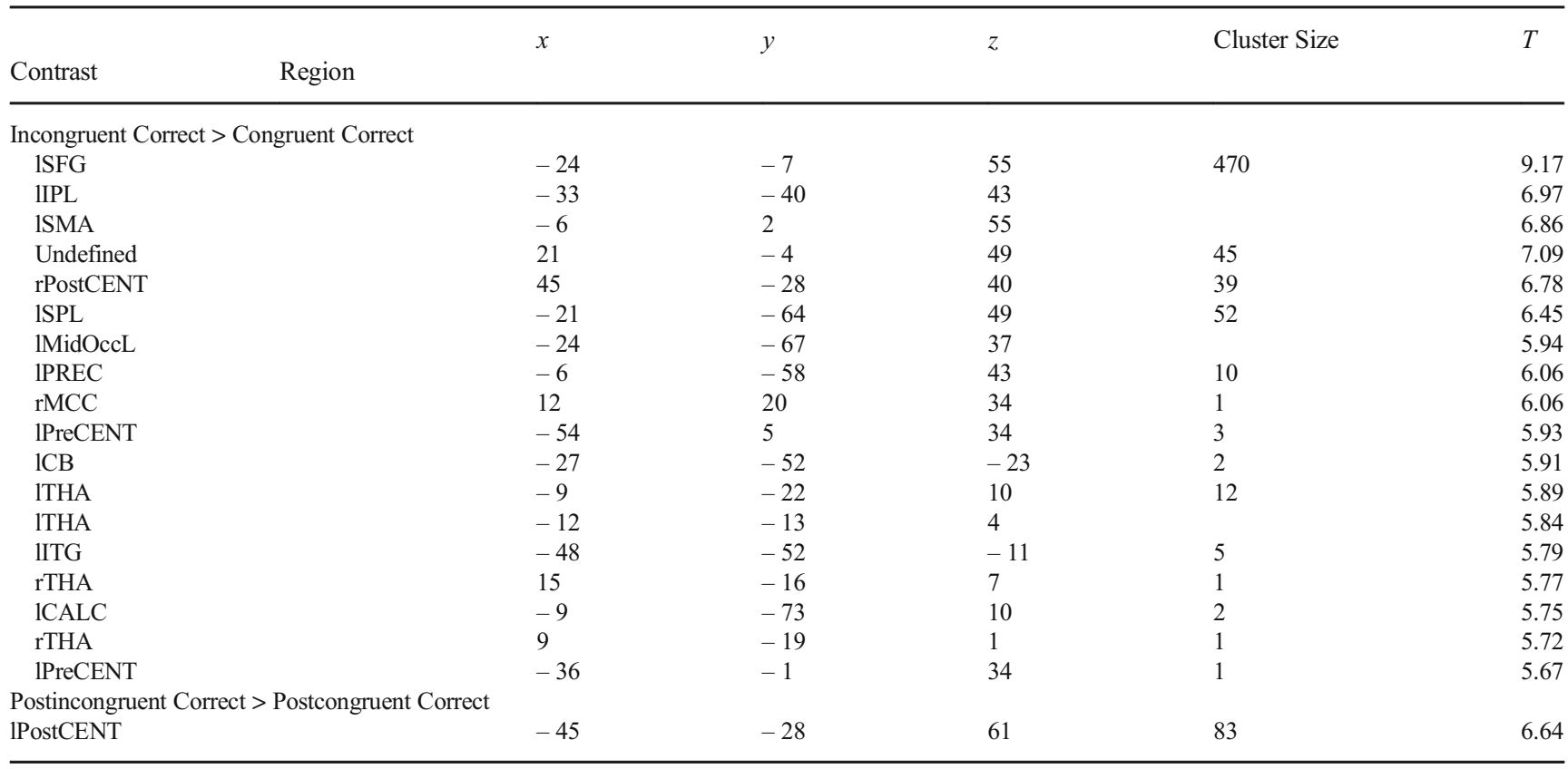

Degrees of freedom $[1,138] ; \mathrm{r}=$ right; 1 = left; $\mathrm{SFG}=$ superior frontal gyrus; $\mathrm{IPL}=$ inferior parietal lobe; SMA = supplemental motor area; PostCENT = postcentral gyrus; $\mathrm{SPL}=$ superior parietal lobe; $\mathrm{MidOccL}=$ middle occipital lobe; $\mathrm{PREC}=$ precuneus MCC $=$ middle cingulate cortex; PreCENT $=$ precentral gyrus; $\mathrm{CB}=$ cerebellum; $\mathrm{THA}=$ thalamus; $\mathrm{ITG}=$ inferior temporal gyrus; $\mathrm{CALC}=$ calcarine

Table 8 Multilevel logistic regression results: Predicting SCFs from desire strength, conflict strength, and conflict-related brain activity

\begin{tabular}{lllllll}
\hline & \multicolumn{1}{l}{$b_{\log }(p)$} & & & & & \\
\cline { 2 - 7 } Level-2 Predictor & Intercept & Desire Strength & Conflict Strength & ROI & ROI $\times$ Desire Strength & ROI $\times$ Conflict Strength \\
\hline PMN ROI & $-0.12(.364)$ & $0.39(<.001)$ & $-0.86(<.001)$ & $0.12(.163)$ & $0.04(.511)$ & $0.14(.175)$ \\
\hline
\end{tabular}

Population-average model with robust standard errors for $N=139$ participants, using $z$-standardized predictors. $b_{\log }=$ predicted log odds; PMN $=$ performance monitoring network (aMCC/SMA, aINS); ROI = region of interest. 


\section{References}

Aarts, K., De Houwer, J., \& Pourtois, G. (2012). Evidence for the automatic evaluation of self-generated actions. Cognition, 124, 117127.https://doi.org/10.1016/j.cognition.2012.05.009

Alexander, W. H., \& Brown, J. W. (2011). Medial prefrontal cortex as an action-outcome predictor. Nature Neuroscience, 14, 13381344.https://doi.org/10.1038/nn.2921

Aron, A. R., Robbins, T. W., \& Poldrack, R. A. (2014). Inhibition and the right inferior frontal cortex: One decade on. Trends in Cognitive Sciences, 18, 177-185.https://doi.org/10.1016/j.tics.2013.12.003

Baumeister, R. F., Vohs, K. D., \& Tice, D. M. (2007). The strength model of self-control. Current Directions in Psychological Science, 16, 351-355.https://doi.org/10.1111/j.1467-8721.2007.00534.x

Berkman, E. T., \& Falk, E. B. (2013). Beyond brain mapping: Using neural measures to predict real-world outcomes. Current Directions in Psychological Science, 22, 45-50.https://doi.org/10. 1177/0963721412469394

Berkman, E. T., Falk, E. B., \& Lieberman, M. D. (2011). In the trenches of real-world self-control: Neural correlates of breaking the link between craving and smoking. Psychological Science, 22, 498506.https://doi.org/10.1177/0956797611400918

Berkman, E. T., Kahn, L. E., \& Merchant, J. S. (2014). Training-induced changes in inhibitory control network activity. Journal of Neuroscience, 34, 149-157.https://doi.org/10.1523/JNEUROSCI. 3564-13.2014

Bertrams, A., \& Dickhäuser, O. (2009). Messung dispositioneller Selbstkontroll-Kapazität: Eine deutsche Adaptation der Kurzform der Self-Control Scale (SCS-K-D) [Measuring dispositional selfcontrol capacity. A German adaptation of the short form of the Self-Control Scale (SCS-K-D)]. Diagnostica, 55, 2-10.https://doi. org/10.1026/0012-1924.55.1.2

Botvinick, M. M., Braver, T. S., Barch, D. M., Carter, C. S., \& Cohen, J. D. (2001). Conflict monitoring and cognitive control. Psychological Review, 108, 624-652.https://doi.org/10.1037/0033-295X.108.3. 624

Bühringer, G., Kräplin, A., \& Behrendt, S. (2012). Universal characteristics and consequences of the addiction syndrome. In H. J. Shaffer, D. A. LaPlante, \& S. E. Nelson (Eds.), APA addiction syndrome handbook, Vol. 1: Foundations, influences, and expressions of addiction (Vol. 1, pp. 291-316). Washington, DC; American Psychological Association.

Bühringer, G., Wittchen, H.-U., Gottlebe, K., Kufeld, C., \& Goschke, T. (2008). Why people change? The role of cognitive-control processes in the onset and cessation of substance abuse disorders. International Journal of Methods in Psychiatric Research, 17, S4S15.https://doi.org/10.1002/mpr.246

Bush, G., Whalen, P. J., Rosen, B. R., Jenike, M. A., McInerney, S. C., \& Rauch, S. L. (1998). The counting Stroop: An interference task specialized for functional neuroimaging - Validation study with functional MRI. Human Brain Mapping, 6, 270-282.https://doi. org/10.1002/(SICI)1097-0193(1998)6:4<270::AID-HBM6>3.0. $\mathrm{CO} ; 2-0$

Carey, S. E., Nestor, L., Jones, J., Garavan, H., \& Hester, R. (2015). Impaired learning from errors in cannabis users: Dorsal anterior cingulate cortex and hippocampus hypoactivity. Drug and Alcohol Dependence, 155, 175-182. https://doi.org/10.1016/j.drugalcdep. 2015.07.671

Craig, A.D.B (2009). How do you feel-now? The anterior insula and human awareness. Nature Reviews Neuroscience, 10, 59-70. https:// doi.org/10.1038/nrn2555

Danielmeier, C., \& Ullsperger, M. (2011). Post-error adjustments. Frontiers in Psychology, 2, 233. https://doi.org/10.3389/fpsyg. 2011.00233
Dreisbach, G., \& Fischer, R. (2012). Conflicts as aversive signals. Brain and Cognition, 78, 94-98. https://doi.org/10.1016/j.bandc.2011.12. 003

Duckworth, A. L., \& Kern, M. L. (2011). A meta-analysis of the convergent validity of self-control measures. Journal of Research in Personality, 45, 259-268. https://doi.org/10.1016/j.jrp.2011.02.004

Dutilh, G., van Ravenzwaaij, D., Nieuwenhuis, S., van der Maas, Han L. J., Forstmann, B. U., \& Wagenmakers, E.-J. (2012). How to measure post-error slowing: A confound and a simple solution. Journal of Mathematical Psychology, 56, 208-216. https://doi.org/10.1016/j. jmp.2012.04.001

Ebitz, R. B., \& Hayden, B. Y. (2016). Dorsal anterior cingulate: A Rorschach test for cognitive neuroscience. Nature neuroscience, 19, 1278-1279. https://doi.org/10.1038/nn.4387

Fischer, R., Plessow, F., Dreisbach, G., \& Goschke, T. (2015). Individual differences in the context-dependent recruitment of cognitive control: Evidence from action versus state orientation. Journal of Personality, 83, 575-583. https://doi.org/10.1111/jopy.12140

Goschke, T. (2014). Dysfunctions of decision-making and cognitive control as transdiagnostic mechanisms of mental disorders: Advances, gaps, and needs in current research. International Journal of Methods in Psychiatric Research, 23(Suppl. 1), 41-57. https://doi. org/10.1002/mpr. 1410

Goschke, T., \& Bolte, A. (2018). A dynamic perspective on intention, conflict, and volition: Adaptive regulation and emotional modulation of cognitive control dilemmas. In N. Baumann, M. Kazén, M. Quirin, \& S. L. Koole (Eds.), Why people do the things they do: Building on Julius Kuhl's contribution to motivation and volition psychology (pp. 111-130). Göttingen, Germany: Hogrefe.

Grinband, J., Savitskaya, J., Wager, T. D., Teichert, T., Ferrera, V. P., \& Hirsch, J. (2011). The dorsal medial frontal cortex is sensitive to time on task, not response conflict or error likelihood. NeuroImage, 57, 303-311. https://doi.org/10.1016/j.neuroimage. 2010.12.027

Heatherton, T. F., \& Wagner, D. D. (2011). Cognitive neuroscience of self-regulation failure. Trends in Cognitive Sciences, 15, 132-139. https://doi.org/10.1016/j.tics.2010.12.005

Hofmann, W., Baumeister, R. F., Förster, G., \& Vohs, K. D. (2012). Everyday temptations: An experience sampling study of desire, conflict, and self-control. Journal of Personality and Social Psychology, 102, 1318-1335. https://doi.org/10.1037/a0026545

Hofmann, W., Schmeichel, B. J., \& Baddeley, A. D. (2012). Executive functions and self-regulation. Trends in Cognitive Sciences, 16, 174-180. https://doi.org/10.1016/j.tics.2012.01.006

Holroyd, C. B., \& Coles, M. G. H. (2002). The neural basis of human error processing: Reinforcement learning, dopamine, and the errorrelated negativity. Psychological Review, 109, 679-709. https://doi. org/10.1037/0033-295X.109.4.679

Holroyd, C. B., \& Yeung, N. (2012). Motivation of extended behaviors by anterior cingulate cortex. Trends in Cognitive Sciences, 16, 122128. https://doi.org/10.1016/j.tics.2011.12.008

Hox, J. J. (2010). Multilevel analysis: Techniques and applications (Quantitative Methodology series), 2nd ed. New York, NY: Routledge.

Inzlicht, M., Bartholow, B. D., \& Hirsh, J. B. (2015). Emotional foundations of cognitive control. Trends in Cognitive Sciences, 19, 126132. https://doi.org/10.1016/j.tics.2015.01.004

Inzlicht, M., Legault, L., \& Teper, R. (2014). Exploring the mechanisms of self-control improvement. Current Directions in Psychological Science, 23, 302-307. https://doi.org/10.1177/0963721414534256

Jha, A. P., Krompinger, J., \& Baime, M. J. (2007). Mindfulness training modifies subsystems of attention. Cognitive, Affective, \& Behavioral Neuroscience, 7, 109-119. https://doi.org/10.3758/CABN.7.2.109

Jostmann, N. B., \& Koole, S. L. (2007). On the regulation of cognitive control: Action orientation moderates the impact of high demands in Stroop interference tasks. Journal of Experimental Psychology. 
General, 136, 593-609. https://doi.org/10.1037/0096-3445.136.4. 593

Karbach, J., \& Verhaeghen, P. (2014). Making working memory work: A meta-analysis of executive-control and working memory training in older adults. Psychological Science, 25, 2027-2037. https://doi.org/ 10.1177/0956797614548725

Kerns, J. G., Cohen, J. D., MacDonald, A. W., Cho, R. Y., Stenger, V. A., \& Carter, C. S. (2004). Anterior cingulate conflict monitoring and adjustments in control. Science, 303, 1023-1026. https://doi.org/10. 1126/science. 1089910

King, J. A., Korb, F. M., von Cramon, D. Y., \& Ullsperger, M. (2010). Post-error behavioral adjustments are facilitated by activation and suppression of task-relevant and task-irrelevant information processing. Journal of Neuroscience, 30, 12759-12769. https://doi.org/10. 1523/JNEUROSCI.3274-10.2010

Klein, T. A., Endrass, T., Kathmann, N., Neumann, J., von Cramon, D. Y., \& Ullsperger, M. (2007). Neural correlates of error awareness. NeuroImage, 34, 1774-1781. https://doi.org/10.1016/j.neuroimage. 2006.11.014

Klingberg, T. (2010). Training and plasticity of working memory. Trends in Cognitive Sciences, 14, 317-324. https://doi.org/10.1016/j.tics. 2010.05 .002

Kool, W., McGuire, J. T., Wang, G. J., \& Botvinick, M. M. (2013). Neural and behavioral evidence for an intrinsic cost of self-control. PLoS ONE, 8, e72626. https://doi.org/10.1371/journal.pone.0072626

Kotabe, H. P., \& Hofmann, W. (2015). On integrating the components of self-control. Perspectives on Psychological Science, 10, 618-638. https://doi.org/10.1177/1745691615593382

Kuhl, J., \& Beckmann, J. (1994). Volition and personality: Action versus state orientation. Göttingen, Germany: Hogrefe \& Huber

Lopez, R. B., Hofmann, W., Wagner, D. D., Kelley, W. M., \& Heatherton, T. F. (2014). Neural predictors of giving in to temptation in daily life. Psychological Science, 25, 1337-1344. https://doi.org/10.1177/ 0956797614531492

Luijten, M., Machielsen, M. W., Veltman, D. J., Hester, R., de Haan, L., \& Franken, I. H. (2014). Systematic review of ERP and fMRI studies investigating inhibitory control and error processing in people with substance dependence and behavioural addictions. Journal of Psychiatry \& Neuroscience. https://doi.org/10.1503/jpn.130052

Miller, E. K., \& Cohen, J. D. (2001). An integrative theory of prefrontal cortex function. Annual Review of Neuroscience, 24, 167-202. https://doi.org/10.1146/annurev.neuro.24.1.167

Mischel, W., Ayduk, O., Berman, M. G., Casey, B. J., Gotlib, I. H., Jonides, J.,... Shoda, Y. (2010). "Willpower" over the life span: Decomposing self-regulation. Social Cognitive and Affective Neuroscience, 6, 252-256. https://doi.org/10.1093/scan/nsq081

Mrazek, M. D., Franklin, M. S., Phillips, D. T., Baird, B., \& Schooler, J. W. (2013). Mindfulness training improves working memory capacity and GRE performance while reducing mind wandering. Psychological Science, 24, 776-781. https://doi.org/10.1177/ 0956797612459659

Neta, M., Schlaggar, B. L., \& Petersen, S. E. (2014). Separable responses to error, ambiguity, and reaction time in cingulo-opercular task control regions. NeuroImage, 99, 59-68. https://doi.org/10.1016/j. neuroimage.2014.05.053

Rabbitt, P. M. (1966). Errors and error correction in choice-response tasks. Journal of Experimental Psychology, 71, 264-272. doi: https://doi.org/10.1037/h0022853

Raudenbush, S. B., Cheong, A., Congdon, Y., \& DuToit, R. M. (2011). HLM7: Hierarchical linear and nonlinear modeling. Lincolnwood, IL: Scientific Software International.
Ridderinkhof, K. R., Ullsperger, M., Crone, E. A., \& Nieuwenhuis, S. (2004). The role of the medial frontal cortex in cognitive control. Science, 306, 443-447. https://doi.org/10.1126/science.1100301

Saunders, B., Lin, H., Milyavskaya, M., \& Inzlicht, M. (2017). The emotive nature of conflict monitoring in the medial prefrontal cortex. International Journal of Psychophysiology, 119, 31-40. https://doi. org/10.1016/j.ijpsycho.2017.01.004

Saunders, B., Rodrigo, A. H., \& Inzlicht, M. (2016). Mindful awareness of feelings increases neural performance monitoring. Cognitive, Affective, \& Behavioral Neuroscience, 16, 93-105. https://doi.org/ 10.3758/s13415-015-0375-2

Schroeder, S. A. (2007). We can do better-Improving the health of the American people. New England Journal of Medicine, 357, 12211228. https://doi.org/10.1056/NEJMsa073350

Shenhav, A., Botvinick, M. M., \& Cohen, J. D. (2013). The expected value of control: An integrative theory of anterior cingulate cortex function. Neuron, 79, 217-240. https://doi.org/10.1016/j.neuron. 2013.07.007

Sridharan, D., Levitin, D. J., \& Menon, V. (2008). A critical role for the right fronto-insular cortex in switching between central-executive and default-mode networks. Proceedings of the National Academy of Sciences, 105, 12569-12574. https://doi.org/10.1073/pnas. 0800005105

Tangney, J. P., Baumeister, R. F., \& Boone, A. L. (2004). High selfcontrol predicts good adjustment, less pathology, better grades, and interpersonal success. Journal of Personality, 72, 271-324. https://doi.org/10.1111/j.0022-3506.2004.00263.x

Tzourio-Mazoyer, N., Landeau, B., Papathanassiou, D., Crivello, F., Etard, O., Delcroix, N.,... Joliot, M. (2002). Automated anatomical labeling of activations in SPM using a macroscopic anatomical parcellation of the MNI MRI single-subject brain. NeuroImage, 15, 273-289. https://doi.org/10.1006/nimg.2001.0978

Uddin, L. Q. (2015). Salience processing and insular cortical function and dysfunction. Nature Reviews Neuroscience, 16, 55-61. https://doi. org/10.1038/nrn3857

Ullsperger, M., Danielmeier, C., \& Jocham, G. (2014). Neurophysiology of performance monitoring and adaptive behavior. Physiological Reviews, 94, 35-79. https://doi.org/10.1152/physrev.00041.2012

Ullsperger, M., Harsay, H. A., Wessel, J. R., \& Ridderinkhof, K. R. (2010). Conscious perception of errors and its relation to the anterior insula. Brain Structure and Function, 214, 629-643. https://doi.org/ 10.1007/s00429-010-0261-1

Ullsperger, M., \& von Cramon, D. Y. (2004). Neuroimaging of performance monitoring: Error detection and beyond. Cortex, 40, 593604. https://doi.org/10.1016/S0010-9452(08)70155-2

Wiswede, D., Münte, T. F., Goschke, T., \& Rüsseler, J. (2009). Modulation of the error-related negativity by induction of shortterm negative affect. Neuropsychologia, 47, 83-90. https://doi.org/ 10.1016/j.neuropsychologia.2008.08.016

Witkiewitz, K., Bowen, S., Douglas, H., \& Hsu, S. H. (2013). Mindfulness-based relapse prevention for substance craving. Addictive Behaviors, 38, 1563-1571. https://doi.org/10.1016/j. addbeh.2012.04.001

Wittchen, H. U., Jacobi, F., Rehm, J., Gustavsson, A., Svensson, M., Jönsson, B.,... Steinhausen, H.-C. (2011). The size and burden of mental disorders and other disorders of the brain in Europe 2010. European Neuropsychopharmacology, 21, 655-679. https://doi.org/ 10.1016/j.euroneuro.2011.07.018

Wolff, M., Krönke, K.-M., Venz, J., Kräplin, A., Bühringer, G., Smolka, M. N., \& Goschke, T. (2016). Action versus state orientation moderates the impact of executive functioning on real-life self-control. Journal of Experimental Psychology: General, 145, 1635-1653. https://doi.org/10.1037/xge0000229 